\title{
Can Oak Powdery Mildew Severity be Explained by Indirect Effects of Climate on the Composition of the Erysiphe Pathogenic Complex?
}

\author{
Benoit Marçais, Dominique Piou, Damien Dezette, and Marie-Laure Desprez-Loustau
}

First author: UMR1136 IAM, INRA, Université de Lorraine, Nancy, F-54280 Champenoux, France; second author: Ministère de l'agriculture, de l'agro-alimentaire et de la forêt DGAL-SDQPV, Département de la Santé des Forêts, 251 rue de Vaugirard, 75732, Paris cedex 15, France; and second, third, and fourth authors: UMR1202 BIOGECO, INRA, University of Bordeaux, F-33610 Cestas, France.

Accepted for publication 16 December 2016.

\begin{abstract}
Coinfection by several pathogens is increasingly recognized as an important feature in the epidemiology and evolution of plant fungal pathogens. Oak mildew is induced by two closely related Erysiphe invasive species (Erysiphe alphitoides and E. quercicola) which differ in their mode of overwintering. We investigated how climate influences the co-occurrence of the two species in oak young stands and whether this is important for the disease epidemiology. We studied the frequency of flag-shoots (i.e., shoots developing from infected buds, usually associated with E. quercicola) in 95 oak regenerations over a 6-year period. Additionally, in 2012 and 2013, the oak mildew severity and the two Erysiphe spp. relative fre-

the proportion of Erysiphe lesions with E. quercicola presence were related to climate. We showed that survival of E. quercicola was improved after mild winters, with increase of both the flag-shoot frequency and the proportion of Erysiphe lesions with E. quercicola presence in spring. However, disease severity was not related to any complementarity effect between the two Erysiphe spp. causing oak powdery mildew. By contrast, increased E. alphitoides prevalence in spring was associated with higher oak mildew severity in autumn. Our results point out the critical role of between-season transmission and primary inoculum to explain disease dynamics which could be significant in a climate-warming context.
\end{abstract} quencies were determined in both spring and autumn in 51 regenerations and 43 1-year-old plantations of oaks. Both the frequency of flag-shoots and
Additional keywords: cryptic species, Erysiphe quercicola, Quercus.
For a long time, plant pathologists have focused on pairwise interactions involving one host and one pathogen species. However, plants, even more than animals, can be individually infected by a wide variety of pathogens affecting the same or different organs (Agrios 2005; Seabloom et al. 2010). For example, even a single leaf may host a necrotrophic pathogen, a rust, and a powdery mildew, as seen in cereals (Fitt et al. 2006). Beyond multiple infections caused by visibly different pathogens, the availability of molecular markers revealed that coinfection in plants is far more common than previously thought, because an individual plant can be coinfected by different genotypes of the same pathogen species (López-Villavicencio et al. 2007; Susi et al. 2015; Tollenaere et al. 2012) but also by different morphologically nondistinguishable species (so-called cryptic species) (Fitt et al. 2006). Indeed, many plant diseases have been shown to be caused by a complex of very closely related (sibling) species, especially of fungi and fungal-like organisms, causing more or less similar symptoms, although with some differences in biology or ecology. Examples include pathogens attacking leaves such as Mycosphaerella spp., fine roots such as Phytophthora spp., or bark such as Botryosphaeria spp. (Crous et al. 2004; Pérez et al. 2012; Vettraino et al. 2002; Xu et al. 2015). These cryptic species can coexist in the same plant and, occasionally, in the same lesion, as was shown for Dothistroma needle blight of pines (Fabre et al. 2012) or Phyllosticta spp. associated with freckle disease of banana (Wong et al. 2012).

Taking into account the combined effects of different pathogens coinfecting the same plants is necessary when considering impacts

Corresponding author: B. Marçais; E-mail address: benoit.marcais@inra.fr

*The $\boldsymbol{e}$-Xtra logo stands for "electronic extra" and indicates that one supplementary figure is published online.

This article is in the public domain and not copyrightable. It may be freely reprinted with customary crediting of the source. The American Phytopathological Society, 2017. on yield and conceiving integrated pest management for crop plants (Savary et al. 2006) but also to understand the role of pathogens in plant population and community dynamics in natural environments (Hersh et al. 2012). More specifically, interactions between coinfecting parasite species or genotypes within individual hosts will affect the severity of disease symptoms and, hence, host fitness as well as pathogen fitness and, ultimately, the epidemiology and evolution of parasites within the host population (Pedersen and Fenton 2007; Susi et al. 2015; Tollenaere et al. 2016). In recent years, the question of how coinfection may affect disease dynamics and pathogen evolution has gained increased recognition and attention (Johnson and Hoverman 2012; Pedersen and Fenton 2007) and has started to be investigated in plant pathosystems (Fitt et al. 2006; Tollenaere et al. 2016). In particular, synergism between coinfecting strains of the same or different pathogen species, in terms of symptom severity, has been reported for virus infections (Syller 2012) and root- or collarinfecting fungi (Marçais et al. 2011, 2016). However, coinfections may also result in milder symptoms, which shows the complexity of interactions involving coinfecting pathogens and the plant response (Tollenaere et al. 2016). Moreover, a few studies have demonstrated that environmental conditions can affect coinfection levels. This is particularly the case when the coinfecting species differ slightly in their environmental preferences. Hence, coinfection levels are expected to be higher in conditions allowing both species to develop or in fluctuating environments alternatively favoring one and the other species. For example, the co-occurrence and relative frequency of two species causing wheat Septoria disease over a 160years period was shown to vary in association with changes in atmospheric $\mathrm{SO}^{2}$ (Bearchell et al. 2005). Climatic conditions affect the co-occurrence of Leptosphaeria maculans and L. biglobosa, causal agents of Phoma stem cankers (Fitt et al. 2006), and of Dothistroma spp. affecting pines (Fabre et al. 2012). Environmental effects, in particular climatic effects, together with host-related effects, may explain the variable levels of coinfection observed for a given plant pathosystem in space and time (Tollenaere et al. 2016). 
Here, we focus on oak powdery mildew, which is a very common and occasionally damaging disease of European forests (Lonsdale 2015; Marçais and Desprez-Loustau 2014). The disease was shown to be caused by a complex of several Erysiphe spp., among which Erysiphe alphitoides and E. quercicola are the most common in France (Mougou et al. 2008; Mougou-Hamdane et al. 2010). The two species produce similar foliar symptoms during the growing season and, therefore, are indistinguishable in the field. Both species can be found on the same tree, on the same leaf, and even in the same lesion (Mougou-Hamdane et al. 2010). However, they differ in their temporal dynamics, with E. quercicola appearing first in spring and E. alphitoides becoming dominant in summer (Feau et al. 2012). This temporal pattern is likely explained by differences in the mode of overwintering of the two species: E. quercicola is the only species detected in flag-shoots, corresponding to the development of buds infected in the previous season, as was also described in apple or grapevine powdery mildew (Délye and Corio-Costet 1998; Jarvis et al. 2002). In contrast, chasmothecia, the sexual fruiting bodies formed on senescing leaves, were always identified as E. alphitoides (Feau et al. 2012; Marçais et al. 2009). Oak powdery mildew shows large spatiotemporal variation in disease severity, because severe epidemics are only observed in some regions and years. As is often hypothesized for such patterns in plant diseases, a relationship was sought between occurrence or severity of the disease and meteorological variables. Only winter variables were significantly related with disease (i.e., disease peaks occurred after mild winters, with mean winter temperatures greater than $9^{\circ} \mathrm{C}$ ) (Marçais and Desprez-Loustau 2014). This result may seem unexpected for a polycyclic foliar pathogen for which climatic factors during the growing season are thought more likely to affect disease dynamics. However, the crucial role of the dormant-season processes in disease dynamics of pathogens which cannot persist on their host all year round has probably been highly underestimated (Tack and Laine 2014). Based on the characteristics of the two Erysiphe spp., we elaborated a general hypothesis based on two propositions which could explain the relationship between winter temperature and disease severity. First, we hypothesized that E. quercicola survival is favored by warmer winters, as was reported for other powdery mildews (Spotts and Chen 1984). Better survival of E. quercicola should translate into greater occurrence of flagshoots, thus favoring the initiation of annual epidemics in spring following mild winters. Second, we hypothesized a complementarity effect between the two pathogen species, whereby E. quercicola predominantly infects the first oak flush (in May to June), and E. alphitoides the second flush (in July to September), resulting in greater overall disease severity when both species co-occur. The complementarity effect has been invoked in ecology to explain the better productivity of diverse plant communities through niche partitioning or positive interactions between species allowing increased resource use (Loreau and Hector 2001). Here, we extend this concept to host resource use by different pathogen species, as was also proposed by Johnson and Hoverman (2012). Specifically, we tested whether (i) variation in flag-shoot and E. quercicola occurrence between years and sites was related to winter temperatures and (ii) oak powdery mildew severity was related to the co-occurrence of E. alphitoides and E. quercicola.

\section{MATERIALS AND METHODS}

Study sites. Two networks of forest plots monitored by the technicians of the French forest health service, the Département de la Santé des Forêts (DSF), were used. Plots distributed all over France (Fig. 1) contained young oak plants (Quercus robur or $Q$. petraea), which are the most susceptible stage to oak powdery mildew (Marçais and Desprez-Loustau 2014), either issued from natural regeneration or from plantations. The first set of plots, hereafter referred to as the regeneration survey, was performed in stands originating from seed trees monitored during 1 to 4 years (height of 10 to $250 \mathrm{~cm}$ ). Two stands were surveyed in 2005 to 2007 , 28 in 2008, 37 in 2009, 36 in 2010, 38 in 2011, 38 in 2012, and 34 in 2013. Altogether, 95 different stands were surveyed, with 31 being pure $Q$. robur, 31 pure $Q$. petraea, and 33 mixed Q. robur/Q. petraea stands. The second set of plots was selected from a larger survey of plantation success carried out by the DSF since 2007 wherein, each year, a sample of plantations established during the preceding winter were observed. This survey, referred to as the plantation survey, was done in 2012 ( 17 stands of $Q$. petraea and 3 of $Q$. robur) and 2013 (19 stands of $Q$. petraea and 4 of $Q$. robur).

Monitoring of the flag-shoot symptom. This part of the study was done in the regeneration survey plots only. The number of flag-shoots was recorded on three 100-m-long transects per plot, with a width of the observed area of approximately $1.5 \mathrm{~m}$ (i.e., a total observed area of $450 \mathrm{~m}^{2} / \mathrm{plot}$ ). Flag-shoots were defined as early developing shoots from the first growth unit for which both the emerging shoot and leaves are almost completely covered with powdery mildew; this pattern is assumed to be related to bud infection in the previous year. The density of oak saplings was estimated on several $1-\mathrm{m}^{2}$ quadrats by transect; on the same quadrats, the maximal height of saplings present in each quadrat was determined. The mean oak sapling density and mean height per transect was computed. Oak species composition of each transect (i.e., the ratio $Q$. robur $/(Q$. petraea $+Q$. robur $))$ was assessed according to a five-degree scale, where $1=>90,2=60$ to $90,3=40$ to $60,4=10$ to 40 , and $5=<10 \% Q$. robur. In early spring of each year, shortly after bud-break, the total number of flag-shoots per transect was counted. In all, $80 \%$ of the surveys were done between 1 and 23 May.

In 2012 to 2013, the density of trees per hectare that were left in the stand to provide acorns during the regeneration process as well as the number of flag-shoots that were located under these seed trees were recorded.

Relationship between Erysiphe spp. and disease severity. This part of the study was performed over 2 years (2012 to 2013) in both regeneration and plantation survey plots. In each year, observations and samplings were made at two periods: in early season (May to June) and late summer (September to October). At these two dates, symptoms were assessed. This was done on 30 saplings distributed along each of the three transects (approximate distance of $10 \mathrm{~m}$ between saplings) in regeneration survey plots. In plantation survey plots, 10 groups of 10 adjacent saplings were

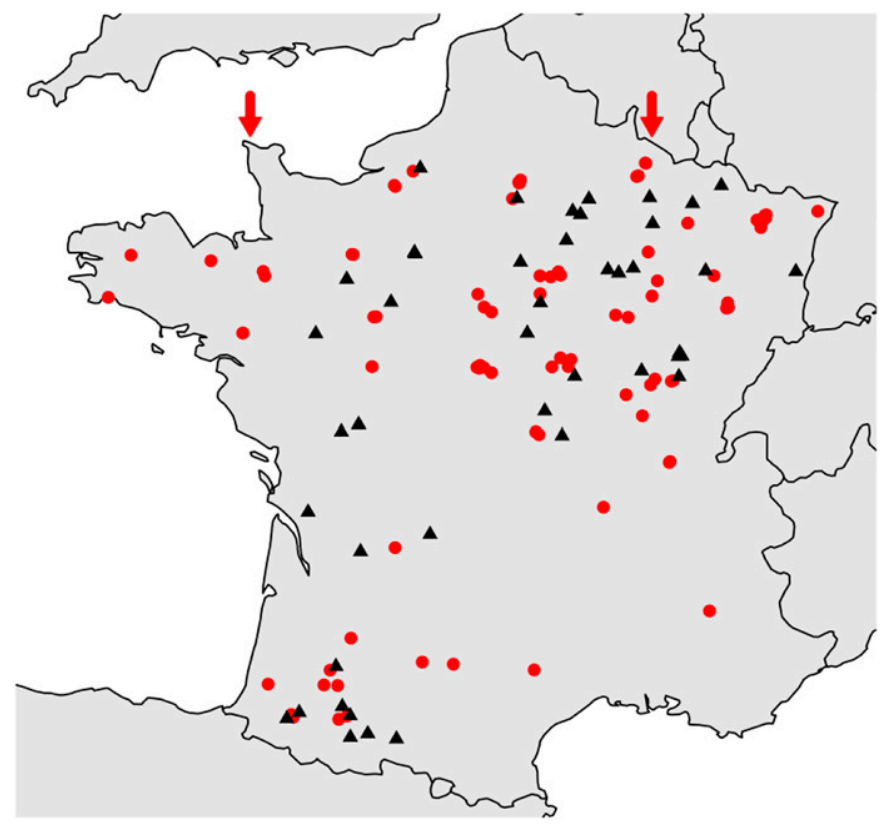

Fig. 1. Location of survey plots. Symbols: $=$ regeneration survey and $\boldsymbol{\Delta}=$ plantation survey. Arrows show the longitude of -1.66 and 5.00 (epsg 4326). 
monitored; the groups were sampled $50 \mathrm{~m}$ apart on two parallel lines separated by $50 \mathrm{~m}$. Infection on each sapling or plant was assessed on a five-grade score, where $0=$ noninfection and $1=0$ to $5,2=5$ to $25,3=25$ to 50 , and $4=50$ to $100 \%$ of total leaf surface infected. Also, at each date, samples of two to three infected leaves were taken from 10 different saplings or plants in each plot and sent to the laboratory for molecular analysis.

Identification of powdery mildew species. Ten sporulating lesions (approximately $0.5 \mathrm{~cm}^{2}$ ) from different plants within each plot at each sampling point underwent polymerase chain reaction (PCR) for identification of Erysiphe spp. (E. alphitoides or E. quercicola), based upon polymorphisms in the ribosomal DNA sequence. The protocol for DNA extraction and PCR was the same as described by Feau et al. (2012), except that forward EryF (Mougou-Hamdane et al. 2010) and reverse o-microrev (Heuser and Zimmer 2002) primers were used. Amplicons were sequenced using Sanger technology and sequences were aligned and analyzed with BioEdit to characterize the two diagnostic single-nucleotide polymorphisms between E. alphitoides and E. quercicola, which were shown to provide accurate identification at the species level (Feau et al. 2011). Valid sequences were obtained for 317 samples from 22 plots and 441 samples from 29 plots in the regeneration survey in 2012 and 2013, respectively, and 370 samples from 21 plots and 449 samples from 26 plots for the plantation survey in 2012 and 2013, respectively.

Systematic sampling of flag-shoots for Erysiphe spp. identification was performed in 2008 and 2009 in many of the stands studied here and was reported by Feau et al. (2012). Because they showed a strict association of this symptom with $E$. quercicola, no further extensive sampling was done in 2010 to 2013. Moreover, because they are rather infrequent, sampling of flag-shoots might have interfered with the dynamics of E. quercicola that we wished to characterize in 2012 to 2013. However, because a high frequency of flag-shoots was observed in some plots in 2013, nine samples from three different plots were analyzed that year; only E. quercicola was detected in all nine.

Statistical analyses. Model of flag-shoot occurrence. Preliminary analyses showed that the frequency of flag-shoots is highly related to sapling height (Supplementary Fig. S1). A Poisson model with a $\log$ link was used, with the number of observed saplings as an offset. This was taken into account by the following equation: $\log$ $\left(\mathrm{nb} \_\mathrm{FS}\right)=\log \left(\mathrm{nb} \_\mathrm{OS}\right)+a-b(\mathrm{He}-\mathrm{c})^{2}$, where nb_FS $=$ the flagshoot number, nb_OS $=$ number of observed saplings, $\mathrm{He}=$ the sapling mean height, $a=$ the flag-shoot number expected at the optimal height, $c=$ the optimal height, and $b=$ the width of height range favorable for flag-shoot occurrence.

In the following analyses, the objective was to study the factors influencing $\exp (a)$, which represents the number of flag-shoots per sapling expected at optimal sapling height (i.e., nb_FS/nb_OS). First, year, geographic effects, and the oak species involved were studied: $\log \left(\mathrm{nb} \_\mathrm{FS}_{\mathrm{ijk}}\right)=\log \left(\mathrm{nb} \_\mathrm{OS}_{\mathrm{ijk}}\right)+\mu+y e(j)+q u\left(\mathrm{oak}_{\mathrm{ijk}}\right)+$ lg.Long ${ }_{\mathrm{i}}+$ lt.Lat $\mathrm{i}+\varepsilon_{\mathrm{i}}-b\left(H e_{\mathrm{ijk}}-c\right)^{2}$, where nb_FS $\mathrm{Fik}_{\mathrm{jk}}$ and nb_OS $\mathrm{ijk}_{\mathrm{i}}=$ the number of flag-shoots and saplings, respectively, observed in transect $k$ of plot $i$ in year $j$ (number of saplings observed is computed as the product of sapling density and observed area); $y e=$ the year effect; oak $_{\mathrm{ijk}}=$ the Quercus spp.; Long $_{\mathrm{i}}$ and Lat ${ }_{\mathrm{i}}=$ longitude and latitude, respectively, expressed in wgs84 (epsg 4326); and $\varepsilon_{I}=a$ random site effect and following a normal distribution $\mathrm{N}\left(0, \sigma^{2}\right)$.

The model was adjusted in a Bayesian framework using Jags 4.2.0 and R library rjags. Noninformative priors were affected to the different parameters: a normal distribution $\mathrm{N}\left(0,10^{4}\right)$ for $y e, q u, l g$, and $l t$; a uniform distribution $\mathrm{U}(0,50)$ for $b$ and $\mathrm{U}(0,2)$ for $c$; and a $\gamma$ distribution $\mathrm{G}(0.001,0.001)$ for $\tau\left(1 / \sigma^{2}\right)$. Three Markov chain Monte Carlo parallel chains with overdispersed initial parameter values were run, with $2.5 \times 10^{6}$ iterations, a burn-in phase of $2.5 \times$ $10^{5}$, and a thinning of $1 / 2,500$. Convergence was checked by a Gelman-Rubin test ( $R_{\text {hat }}$ were close to 1$)$.

In a second stage, the year and geographic variables were replaced by climatic variables. Variables targeting the period of bud formation (in the previous summer), bud survival (winter), and bud burst (spring) were used. The following variables were computed for winter (December, January, and February): MT.win = average of mean daily temperature, MinT.win $=$ minimal temperature reached during the winter, and sNDT.win = the sum of negative minimal daily temperatures. For the spring, we computed MinT.spr minimal temperature reached in April, and TM.spr and SR.spr = mean daily temperature and sum of daily rain, respectively, from 15 April to 15 May. Finally, for the summer of the previous year, we computed TM.sum and TX.sum = average of daily mean and maximal temperature, respectively, in June to August of the previous year and SR.sum $=$ sum of daily rain during the previous summer (June to August). The climatic data were daily data retrieved from the meteorological station of Météo-France closest to the surveyed stands. MinT.win, sNDT.win, and MinT.spr were log transformed before use. Climatic variables were standardized to have a mean of 0 and a variance of 1 before analysis. Each climatic variable was first introduced separately in the model, in addition to the oak species, sapling height, and site random effects. Analyses were performed as previously described.

Finally, a few models with several climatic variables, selected depending on their statistical significance in the previous step, were compared with the model including year, latitude, and longitude. The deviance information criterion (DIC) was used to select the best model (with a lower DIC indicating a better fit to the data).

Model of E. quercicola distribution. The relative frequency of E. quercicola (or E. alphitoides) among infected cases was computed for each date and plot as the proportion FreqEQ $=\left(\mathrm{NbS} \_\mathrm{EQ}+\right.$ NbS_EAQ)/NbS_tot, with NbS_EQ = the number of analyzed samples with detection of $E$. quercicola, $\mathrm{NbS} \_\mathrm{EAQ}=$ the number of analyzed samples with E. quercicola and E. alphitoides, and $\mathrm{NbS}$ tot $=$ the total number of analyzed samples with Erysiphe spp. present (and reciprocally for FreqEA).

Plots of the plantation survey were not included in this analysis because they were 1-year-old plantations and the occurrence of E. quercicola might have reflected more the origin of the seedlings than ecological preferences of this mildew species. Thus, 51 plots of the regeneration survey for which the proportion of Erysiphe lesions with E. quercicola presence was available in 2012 and 2013 were included in the analysis. For each plot, we used the maximal relative frequency of E. quercicola measured among the two dates (in spring in $90 \%$ of the cases). The proportion of lesions with E. quercicola was analyzed with a logistic model, with the same approach as that used for flag-shoots (i.e., a model integrating year and geographic effects first $): \operatorname{Logit}\left(\operatorname{FreqEQ}_{\mathrm{ij}}\right)=\mu+y e(j)+q u\left(\mathrm{oak}_{\mathrm{ij}}\right)+\lg \cdot \operatorname{Long}_{\mathrm{i}}+1 \mathrm{t}$. $\mathrm{Lat}_{\mathrm{i}}+\varepsilon_{\mathrm{i}}-b\left(H e_{\mathrm{ij}}-c\right)^{2}$, where FreqEQ $\mathrm{ij}_{\mathrm{ij}}=$ the proportion of Erysiphe lesions with $E$. quercicola for plot $i$ in year $j$, and the other variables are the same as for the flag-shot model.

In a second step, a model with climatic variables (the same as before) was fitted, one by one first and then combined. Models were fitted in a Bayesian framework as indicated for flag-shoot frequency, except that chains were run with 100,000 iterations, a burn-in phase of 12,000, and a thinning of 1/100.

Relationship between species prevalence, co-occurrence, and disease severity. For each plot, disease prevalence (i.e., the percentage of infected plants [DP] and disease severity [DS]) were computed as: $\mathrm{DS}=\left(\mathrm{Nb} \_\mathrm{rl} .0 .025+\mathrm{Nb} \_\mathrm{r} 2.0 .15+\mathrm{Nb} \_\mathrm{r} 3.0 .375+\right.$ Nb_r4.0.75)/Nb_tot, where Nb_r1, ..., Nb_r4 = the number of plants rated as $1, \ldots, 4$ and $\mathrm{Nb}$ tot $=$ the total number of rated plants. The prevalence of each species was calculated as PrevEA = FreqEA $\times$ DP, where DP is the disease prevalence at the same date (and reciprocally for EQ).

According to our hypothesis, we tested several models where disease severity in summer (assessed in September to October) was explained by variables related to the prevalence of Erysiphe spp. on the first oak flush in spring (May to June). The following models were fitted: Logit $\left(\mathrm{DS} \_\right.$sum $\left._{\mathrm{ij}}\right)=\mu+y e(j)+q u\left(\mathrm{QS}_{\mathrm{i}}\right)+$ pl.Plant $_{\mathrm{i}}+$

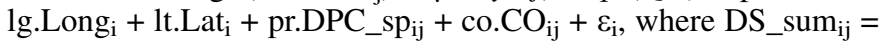
disease severity in summer (second assessment) for plot $i$ in year $j$, 
$\mathrm{QS}_{\mathrm{i}}=$ Quercus $\mathrm{sp}$., Plant $_{\mathrm{i}}=$ the type of stand (1 if a plantation and 0 if a regeneration), Long $_{i}=$ longitude, Lat $_{i}=$ latitude, $D_{P C} s_{i j}=a$ variable related to disease prevalence in spring $j$ in plot $i$ integrating Erysiphe spp. composition, and $\mathrm{CO}_{\mathrm{ij}}=$ a variable measuring the cooccurrence of the two Erysiphe spp. in plot $i$ in year $j$. For $\mathrm{CO}_{\mathrm{ij}}$, we took the Shannon index $\left(-\sum \mathrm{p}_{\mathrm{i}}, \log 2\left[\mathrm{p}_{\mathrm{i}}\right]\right.$, where $\mathrm{p}_{\mathrm{i}}=$ the proportion of Erysiphe lesions with presence of species $i$ ) as an equitability index rated from 0 if only one of the species occurs up to 1 if the two species are equally common. Finally, $\varepsilon_{\mathrm{i}}$ is a random plot effect.

Three expressions of DPC_sp $\mathrm{ij}_{\mathrm{ij}}$ were tested: (i) PrevEA_sp $\mathrm{ij}_{\mathrm{ij}}$, (ii) PrevEQ_sp $\mathrm{ij}_{\mathrm{j}}$, and (iii) Dens_FS $\mathrm{ij}_{\mathrm{ij}}$, where Dens $\mathrm{FS}_{\mathrm{iji}}=$ the number of flag-shoots per square meter (only data from the regeneration survey were used in this case). A $\beta$ distribution was assumed for DS_sum and the model was fitted in a Bayesian framework, using noninformative priors as stated above. The three chains with overdispersed initial values were run with a burn-in period of 20,000 for 200,000 iterations with a thinning of 200 .
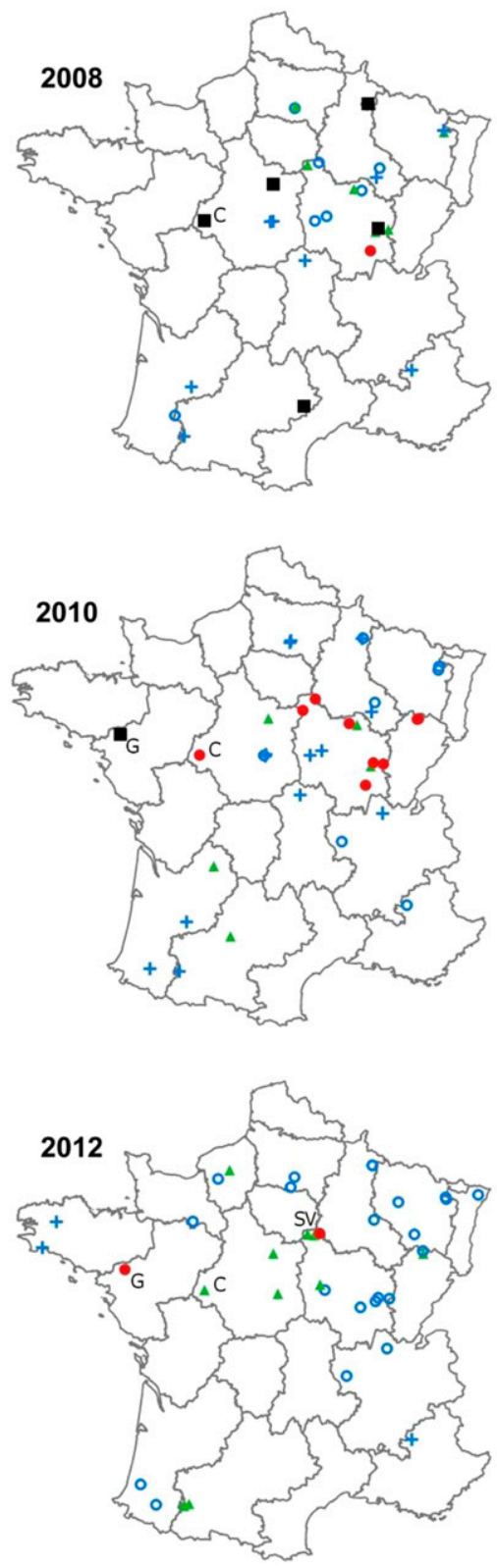

\section{RESULTS}

Climatic and other factors explaining the spatiotemporal distribution of the flag-shoot symptom. Observations during the regeneration survey from 2008 to 2013 are presented in Figure 2.

Flag-shoots were observed in at least 1 year in $55 \%$ of the 95 surveyed plots, with a presence in $77 \%$ of the years in plots where flag-shoots were observed in at least 1 year. However, part of the variability was linked to the sapling height: although flag-shoots were observed in only $16 \%$ of plots with saplings more than $70 \mathrm{~cm}$ in height, they were present in $64 \%$ of plots with saplings less than $70 \mathrm{~cm}$ in height. The occurrence of flag-shoots was always low, with less than 10 flags-shoots per 1,000 saplings in $95 \%$ of the plots. Mean annual number of flag-shoots per 1,000 saplings were 3.6, $3.3,1.7,2.2,0.1$, and 2.4 for the successive years from 2008 to 2013 , respectively, with extremely low values in 2012 (no figures are
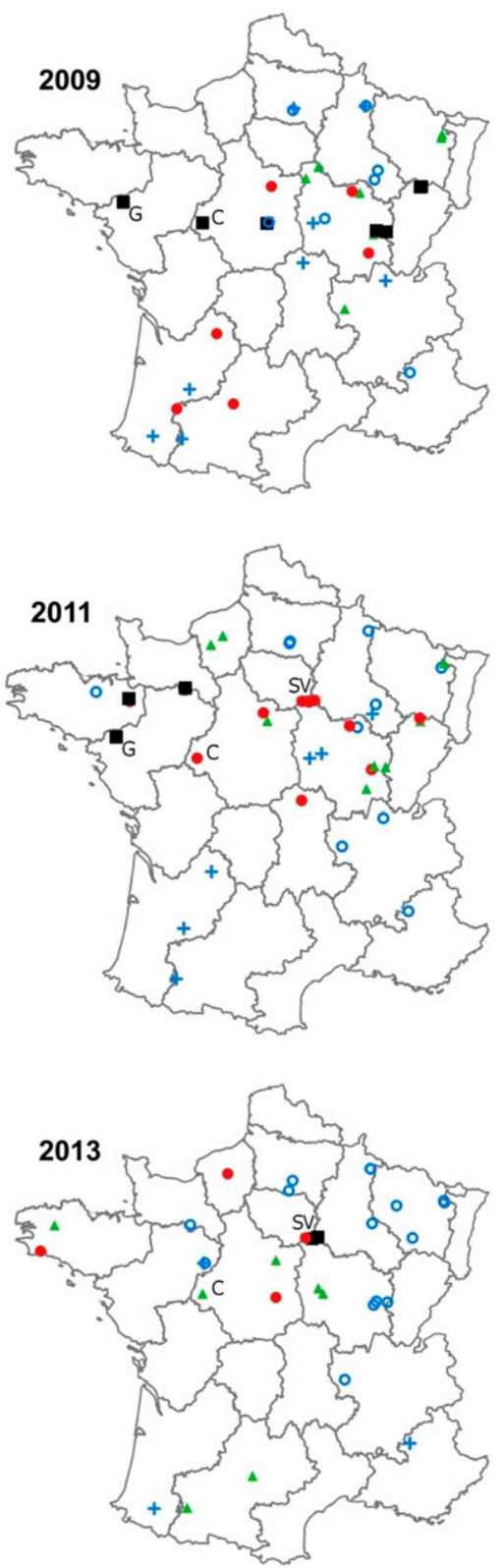

Fig. 2. Frequency of flag-shoots in the surveyed plots in 2008 to 2013. Symbols indicate no flag-shoot presence (O) or 0 to 1.0 ( $\mathbf{\Delta}), 1$ to 5.0 ( (-) flag-shoots per 1,000 saplings; + = plots with saplings of more than $70 \mathrm{~cm}$ height that are very unfavorable to flag-shoot presence. No map for 2005 to 2007 is represented because only one to two plots were surveyed in those years. Plots of Gavre (G), Chinon (C), and Soucy-Voisines (SV) that show consistently high flagshoot frequency are indicated by letters. 
given for years 2005 to 2007 because numbers of observed plots are too low). The mean density of flag-shoots was 1 per $10.6 \mathrm{~m}^{2}$.

There was evidence of temporal autocorrelation in flag-shoot presence. Flag-shoots were observed in $80 \%$ of stands containing flag-shoots in the previous year but in only $10 \%$ of stands where none were observed in the previous year. Some sites showed higher numbers of flag-shoots per 1,000 saplings during several years in a row such as Gavre (10.9 over 4 years), Chinon ( 5 over 6 years), and Soucy-Voisines (6 over 3 years) (Fig. 2).

The general model with all years showed that year, longitude, latitude, and Quercus sp. all had a significant effect on the frequency of flag-shoots. Significantly more flag-shoots are predicted in the western part of the country compared with the east (i.e., decreasing frequency with increasing continentality), in the north than in the south, and in $Q$. petraea compared with $Q$. robur (Table 1). On average over the whole period, the number of flag-shoots per 1,000 saplings was 2.8 on $Q$. petraea but only 0.7 on $Q$. robur. For example, in 2008, the year with the highest flag-shoot occurrence, the mean predicted number of flag-shoots per 1,000 saplings at the optimal sapling height of $36 \mathrm{~cm}$ was 5.3 for pure $Q$. petraea plots and 1.2 for pure $Q$. robur stands at a latitude of 47.65 , in the western part of France (longitude -1.66) (Fig. 1), and less than 1.0 for both oak species in the eastern part of the country (longitude 5) (Fig. 1). In addition, local effects explain a large part of the variation, as shown by the high standard deviation of the random plot effect of 2.6. This explains why, despite a general trend of decreasing frequency from east to west, some plots may present a very high frequency of flag-shoots even in the east of France (Fig. 2).

In 2012 to 2013, some factors that might explain the plot effect were explored and, in particular, the density of seed trees left in the stand (trees left during the regeneration process to provide acorns). This did not significantly influence the flag-shoot frequency; the $\log$ (tree density) effect was -0.077 , with a $95 \%$ credibility interval of [ $-0.243,0.129]$, in a model with 2012 to 2013 data, including year, latitude, oak species, and height effect. However, when seed trees were present in a plot, $71 \%$ of flag-shots were observed below those trees. It has to be pointed out that tree density presented a strong negative correlation with sapling height $(r=-0.391, P<0.001)$. Thus, using the 2012 to 2013 data $(n=273)$, we compared two models including either the tree density or the sapling height effect

TABLE 1. Results of the Poisson regression on flag-shoot frequency in oak regenerations ${ }^{\mathrm{a}}$

\begin{tabular}{lcc}
\hline Variable $^{\mathrm{b}}$ & Mean $(\mathrm{SD})^{\mathrm{c}}$ & $95 \% \mathrm{CI}^{\mathrm{d}}$ \\
\hline$\mu$ & $-18.95(9.22)$ & $-36.77 ;-1.25$ \\
ye (2008) & $1.38(0.07)$ & $1.24 ; 1.52$ \\
ye (2009) & $0.82(0.06)$ & $0.70 ; 0.94$ \\
ye (2010) & $0.25(0.06)$ & $0.14 ; 0.36$ \\
ye (2011) & $-0.66(0.05)$ & $-0.77 ;-0.56$ \\
ye (2012) & $-2.31(0.12)$ & $-2.45 ;-1.99$ \\
$y e(2013)$ & $0.42(0.07)$ & $0.28 ; 0.56$ \\
$l g$ & $-0.23(0.12)$ & $-0.47 ;-0.01$ \\
$l t$ & $0.23(0.11)$ & $0.01 ; 0.46$ \\
$q u(1)$ & $-0.74(0.13)$ & $-1.01 ;-0.49$ \\
$q u(2)$ & $-0.05(0.07)$ & $-0.19 ; 0.09$ \\
$q u(3)$ & $0.79(0.06)$ & $0.61 ; 0.99$ \\
$b$ & $3.19(0.61)$ & $2.04 ; 4.42$ \\
$c$ & $0.36(0.04)$ & $0.29 ; 0.45$ \\
$\sigma$ & $2.57(0.30)$ & $2.04 ; 3.23$ \\
\hline
\end{tabular}

${ }^{a}$ The model deviance information critera (DIC) is 4,657.0.

b No year effects (ye) were computed for 2005 to 2007 because only one to two stands were observed in those years. Abbreviations: $q u(1)=$ pure Quercus robur plots, $q u(2)=\operatorname{mixed} Q$. robur/Q. petraea plots, $q u(3)$, pure $Q$. petraea plots.

c $\mathrm{SD}=$ standard deviation

${ }^{\mathrm{d}} \mathrm{CI}=$ credibility interval. Values for parameters in the following model: $\log \left(\mathrm{nb}_{-} \mathrm{FS}_{\mathrm{ijk}}\right)=\log \left(\mathrm{nb} \_\mathrm{OS} \mathrm{ijk}_{\mathrm{jk}}\right)+m+y e(j)+q u\left(\mathrm{oak}_{\mathrm{ijk}}\right)+\lg \cdot \operatorname{Long}_{\mathrm{i}}+1 \mathrm{t} \cdot \mathrm{Lat}_{\mathrm{i}}+$ $\varepsilon_{\mathrm{i}}-b .\left(H e_{\mathrm{ijk}}-c\right)^{2}$, where Long $_{\mathrm{i}}$ and $\mathrm{Lat}_{\mathrm{i}}$ are the longitude and latitude, respectively, and $\varepsilon_{\mathrm{i}}$ is a random effect with a variance of $\sigma$. in addition to year, oak species, and latitude effects. The second model provided a better fit to the data, with a DIC of 1,172 instead of 1,319 for the first model.

The analyses of flag-shoot frequency in relation to climatic variables, replacing the year and geographic effects in the models, identified several significant variables when tested one by one (Table 2). The most significant was the minimal temperature during winter, with a negative effect of cold temperatures on the frequency of flag-shoots (Fig. 3). The conditions prevailing in the previous growing season may also play a role, because a significant effect of the average daily maximal temperatures during summer (TX.sum) was observed, although a nonlinear relationship seems to better fit the data (Fig. 3). Thus, in the model combining several climatic variables, TX.sum ${ }^{2}$ was entered as well as TX.sum. Indeed, the fitted parameter for TX.sum ${ }^{2}$ was different from 0 in the three models presented in Table 3, indicating that an optimum in TX.sum occurred for flag-shoot frequency, estimated at $22.5^{\circ} \mathrm{C}$ (credibility interval of 22.4 to $22.8^{\circ} \mathrm{C}$, model 3 ). Models combining minimal winter temperature and maximal summer temperature in the previous summer, as well as one other variable representing spring conditions, better fitted the data than models with only one climatic variable (Table 3 ). The best model combined minimal winter temperature and maximal summer temperature (both significant) and a variable related to late frosts (in April). However, it can be observed that this model provided a fit that is inferior to the model with year, latitude, and longitude effects (DIC values of 5,323 compared with 4,657). This suggests that the climatic variables entered in the model only partially explain the spatiotemporal variation observed in flag-shoot frequency.

Climatic and other factors explaining the spatiotemporal distribution of $\boldsymbol{E}$. quercicola $E$. quercicola, alone or in mixture with E. alphitoides, was detected in June in approximately $60 \%$ of stands of the regeneration survey in both 2012 and 2013 (Fig. 4). Positive or negative detection of E. quercicola in June at plot level was associated with the previous observation of flag-shoots in the same stand $\left(\chi^{2} P=0.002\right.$ and 0.09 in 2012 and 2013, respectively). In particular, E. quercicola was detected in most stands in which flag-shoots had been observed (100 and 80\% in 2012 and 2013, respectively).

The proportion of Erysiphe lesions with E. quercicola presence within plots was highest in June 2013, with detection in approximately $50 \%$ of analyzed infected samples (equivalent to $50 \%$ of sampled infected saplings), whereas it was only $23 \%$ in June 2012. The proportion of lesions with E. quercicola was lower at the end of the season in both years (9\% in 2012 and 24\% in 2013) but

TABLE 2. Results of the Poisson models on the relationship between flagshoot frequency in oak regenerations and climatic data (included separately)

\begin{tabular}{lccc}
\hline Model $^{\mathrm{a}}$ & Mean $(\mathrm{SD})^{\mathrm{b}}$ & $95 \% \mathrm{CI}^{\mathrm{c}}$ & $\mathrm{DIC}^{\mathrm{d}}$ \\
\hline SR.sum & $-0.21(0.03)$ & $-0.25 ;-0.16$ & $6,808.4$ \\
TM.sum & $-0.45(0.04)$ & $-0.52 ;-0.37$ & $6,740.1$ \\
TX.sum & $-0.57(0.03)$ & $-0.63 ;-0.51$ & $6,499.8$ \\
$\log (-$ MinT.spr) & $0.13(0.03)$ & $0.08 ; 0.18$ & $6,850.3$ \\
SR.spr & $0.05(0.02)$ & $0.01 ; 0.08$ & $6,870.1$ \\
TM.spr & $-0.03(0.02)$ & $-0.07 ; 0.01$ & $6,875.2$ \\
$\log (-$ SNDT.win) & $-0.87(0.04)$ & $-0.95 ;-0.79$ & $6,376.4$ \\
$\log (-$ MinT.win) & $-0.73(0.02)$ & $-0.78 ;-0.68$ & $5,822.6$ \\
TM.win & $0.11(0.03)$ & $0.04 ; 0.17$ & $6,867.4$ \\
\hline
\end{tabular}

a TM.sum, TX.sum, and SR.sum = average of mean or maximal daily temperature and sum of daily rain, respectively, in the previous year summer; MinT.spr = minimal temperature reached in April; SR.spr and TM.spr = sum of daily rain and average daily mean temperature, respectively, from 15 April to 15 May; TM. win $=$ average of mean daily temperature; MinT.win $=$ minimal temperature reached; and sNDT.win $=$ sum of negative minimal daily temperatures. $R_{\text {hat }}$ were close to 1, indicating that the Markov chain Monte Carlo chains converged (Gelman-Rubin test).

b $\mathrm{SD}=$ standard deviation

c $\mathrm{CI}=$ credibility interval. Values for parameter $\mathrm{cl}$ in the following model: $\log \left(\mathrm{nb} \_\mathrm{FS}_{\mathrm{ijk}}\right)=\log \left(\mathrm{nb}_{-} \mathrm{OS} \mathrm{S}_{\mathrm{ijk}}\right)+m+q u\left(\mathrm{oak}_{\mathrm{ijk}}\right)+\mathrm{cl} \cdot \mathrm{CLIM}_{\mathrm{i}}+\varepsilon_{\mathrm{i}}-b\left(H e_{\mathrm{ijk}}-c\right)^{2}$, where CLIMi are the variables given in $a$.

d Deviance information critera (DIC). 
positively related to the proportion in June in the same stand. The proportion of lesions with E. quercicola presence in June was correlated to the frequency of flag-shoots in the same stand a month before (in May) in both 2012 (Spearman $r$ of $0.664, P<0.001$ ) and 2013 (Spearman $r$ of $0.400, P=0.032$ ). The logistic regression analysis of proportion of Erysiphe lesions with E. quercicola in plots demonstrated significant effects of year, longitude (greater proportion in the western part of the country), host species (greater proportion in $Q$. petraea), and mean sapling height (i.e., effects similar to those identified for the occurrence of flag-shoots) (Table 4; Fig. 5).

When the year and geographic variables were replaced by climatic variables in the model, the only variables significantly related to the proportion of powdery mildew lesions associated with E. quercicola were winter-related temperatures, as previously observed for flag-shoots (Table 5). The single best explaining variable was the sum of negative minimal temperatures below $0^{\circ} \mathrm{C}$ from November to March (sNDT_win). No other model with two or three climatic variables performed better than the one with only sNDT_win. With a DIC of 144.8 , this model performed slightly better than the model with year and geographic variables (DIC of 147.0).

Relationship between the prevalence of the two Erysiphe spp. and disease severity. Disease severity in June 2012 and 2013 in the plots of the regeneration or plantation surveys, expressed as the mean proportion of leaf area infected per sapling, ranged between 0 and 0.5 , with a median of 0.03 . Prevalence in June was 0.32 (interquartile range of [0.04, 0.57]) for E. alphitoides and 0.09 (interquartile range of $[0,0.10]$ ) for E. quercicola. Although flag-shoots were present in $43 \%$ of the regeneration survey stands over these 2 years, the frequency remained low, with only $13 \%$ of the plots having more than 1.0 flag-shoot per 1,000 saplings. Cooccurrence of the two Erysiphe spp. was observed in 55\% of the studied stands. In the June sampling, co-occurrence was present in $7 \%$ of the samples (4\% in the autumn sampling), each sample representing a single leaf.

Disease severity at the end of the season, expressed as the mean proportion of leaf area infected per sapling, was moderate to high in both years at 0.23 (interquartile range of [0.07, 0.37]) (Fig. 5). The analysis of final disease severity during the 2 years could not show any significant effect of the co-occurrence of E. alphitoides and E. quercicola (Table 6) or of either the prevalence of E. quercicola in spring (95\% credibility interval of [-1.50, 0.97], analysis not shown) or the flag-shoot frequency (95\% credibility interval of [-2.16, 0.79], analysis not shown). However, the E. alphitoides prevalence in spring was significantly related to powdery mildew severity in autumn (Table 6), with increasing Erysiphe spp. prevalence in June corresponding to increasing disease severity in
October (Fig. 5A). A large part of the variation remained unexplained, with notably no significant effects of geography, Quercus spp., or type of stand (regeneration or plantation). However, the severity was significantly different between 2012 and 2013, with a similar trend in plantation and regeneration stands (Fig. 5B; Table 6).

\section{DISCUSSION}

Our study showed that the occurrence of both E. quercicola and of the flag-shoot symptoms it causes present a geographic trend in France, with a decreasing frequency eastward. This was associated with an increased frequency of E. quercicola and flag-shoots in years or locations with mild winters, with negative temperatures being the best predictor of observed distributions. This supports our first hypothesis that mild winters may favor good overwintering of E. quercicola in the oak buds. However, our second hypothesis (i.e., that this effect of climate on one of the two species in the pathogenic complex would explain spatiotemporal variations in disease severity) was not supported by the data. Indeed, no relationship was found between relative frequency of $E$. quercicola in spring and severity of oak mildew in the stand at the end of the season. We also found no significant effect of coinfection by the two

TABLE 3. Results of the Poisson models on the relationship between flagshoot frequency in oak regenerations and several climatic variables

\begin{tabular}{llrcc}
\hline Model & \multicolumn{1}{c}{ Variable $^{\mathrm{a}}$} & Mean $(\mathrm{SD})^{\mathrm{b}}$ & $95 \% \mathrm{CI}^{\mathrm{c}}$ & DIC $^{\mathrm{d}}$ \\
\hline 1 & Log(-MinT.win) & $-0.65(0.02)$ & $-0.70 ;-0.60$ & $5,695.0$ \\
& TX.sum & $-0.31(0.03)$ & $-0.37 ;-0.25$ & $\ldots$ \\
\multirow{2}{*}{2} & TX.sum 2 & $-15(0.03)$ & $0.09 ; 0.20$ & $\ldots$ \\
& Log(-MinT.win) & $-0.64(0.03)$ & $-0.69 ;-0.59$ & $5,695.8$ \\
& TX.sum & $-0.30(0.03)$ & $-0.36 ;-0.24$ & $\ldots$ \\
& TX.sum 2 & $0.15(0.03)$ & $0.09 ; 0.20$ & $\ldots$ \\
3 & SR.spr & $0.03(0.03)$ & $-0.03 ; 0.08$ & $\ldots$ \\
& Log(-MinT.win) & $-0.93(0.03)$ & $-0.98 ;-0.87$ & $5,323.0$ \\
& TX.sum & $-0.35(0.03)$ & $-0.41 ;-0.28$ & $\ldots$ \\
& TX.sum 2 & $0.31(0.03)$ & $0.26 ; 0.37$ & $\ldots$ \\
& Log(-MinT.spr) & $-0.30(0.01)$ & $-0.33 ;-0.27$ & $\ldots$ \\
\hline
\end{tabular}

a TX.sum $=$ the average of maximal daily temperature in the previous year summer, SR.spr = the sum of daily rain from 15 April to 15 May, and MinT.win $=$ the minimal temperature reached during winter. $R_{\text {hat }}$ were close to 1 , indicating that the Markov chain Monte Carlo chains converged (Gelman-Rubin test). Very similar estimates for $q u, b$, and $c$ were obtained in the three models. b $\mathrm{SD}=$ standard deviation

c $\mathrm{CI}=$ credibility interval. Models: $\log \left(\mathrm{nb} \_\mathrm{FS}_{\mathrm{ijk}}\right)=\log \left(\mathrm{nb} \_\mathrm{OS}_{\mathrm{ijk}}\right)+m+$ $q u\left(\mathrm{oak}_{\mathrm{ijk}}\right)+\mathrm{A}_{\mathrm{i}}+\varepsilon_{\mathrm{i}}-b\left(H e_{\mathrm{ijk}}-c\right)^{2}$, where $\mathrm{Ai}$ included the variables indicated in $b$. d Deviance information critera (DIC).

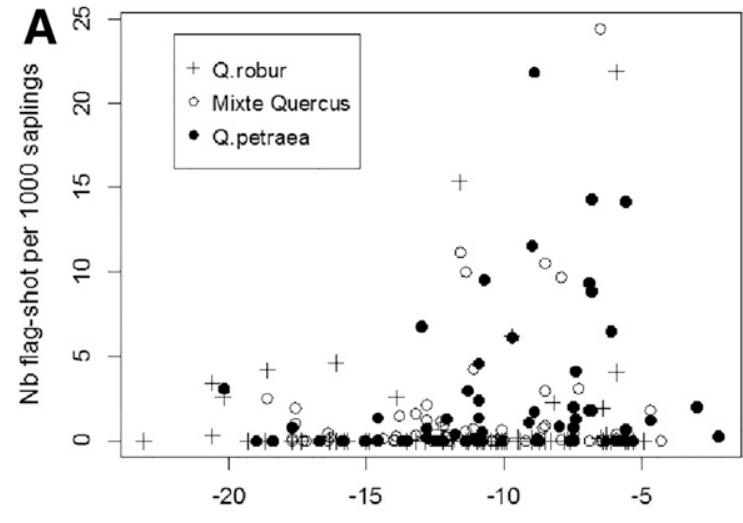

Minimal winter temperature

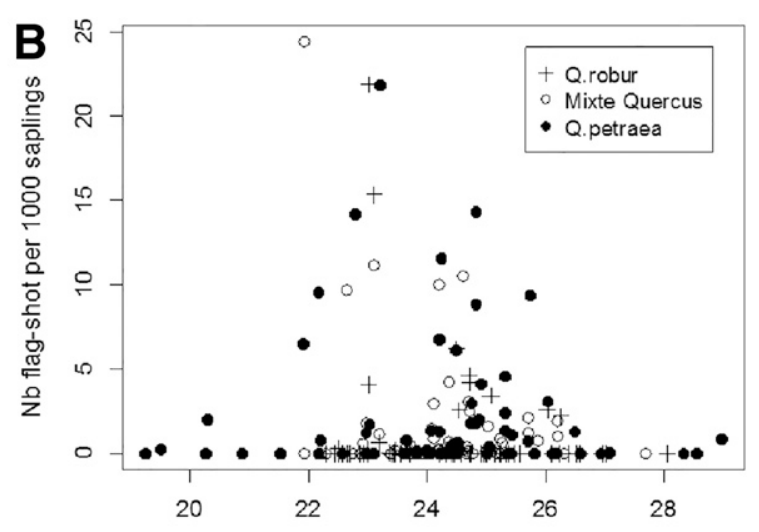

Average Maximal daily summer temperature

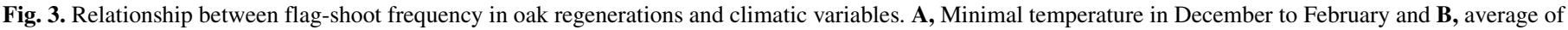
the maximal daily temperature in June to August of the previous summer. 
Erysiphe spp. (E. quercicola and E. alphitoides) on the severity of the disease at the stand level.

Feau et al. (2012) showed that flag-shoots in oak young stands were exclusively associated with E. quercicola. Although we checked the species involved for only a few flag-shoots, our results are in agreement with this: flag-shoots and E. quercicola frequencies were correlated and similar factors (i.e., winter temperature conditions, longitude, oak species, or sapling height) explained both, which strongly suggests a species-symptom link. Thus, flag-shoot frequency can be interpreted as a measure of E. quercicola abundance in the young oak stands. The overall occurrence of flag-shoots in oak regenerations was very low, with mean annual number of 0.1 to 24 per 1,000 saplings. This is substantially lower than the occurrence reported for other powdery mildews of perennial hosts, ranging from 1 to $5 \%$ plants with flag-shoots (Cortesi et al. 2004; Khairi and Preece 1978; Liyanage and Royle 1976) to as high as 80\% (Sall and Wrysinski 1982). However, the frequency in oak stands represented approximately one flag-shoot per $10.6 \mathrm{~m}^{2}$ which, from an epidemiological point of view, is a significant source of inoculum.

The ecology of E. quercicola, recently described in Japan (Takamatsu et al. 2007) and only reported thus far within Europe in France (Mougou-Hamdane et al. 2010), is still very poorly known. A clear result of our study is the negative relationship between low winter temperatures and E. quercicola or flag-shoot occurrence. Distribution of E. quercicola in Japan also suggests adaptation to warmer climates, compared with E. alphitoides (Takamatsu et al. 2015). However, the species could be found all over France, including eastern locations with a rather continental climate, which indicates that the limit for E. quercicola survival was not reached. These results strongly suggest that E. quercicola abundance is explained by overwintering conditions, which are less favorable during cold winters. Lethal effects of very low temperatures on powdery mildew overwintering in buds have been reported for other species (Liyanage and Royle 1976; Spotts and Chen 1984). In particular, for apple powdery mildew, Covey (1969) reported that temperatures below $-20^{\circ} \mathrm{C}$ can destroy the fungus, and Spotts and Chen (1984) showed that buds infected by Podosphaera leucotricha are especially susceptible to frost events occurring in early spring because of deacclimation. Such a mechanism may explain the relationship we found between flag-shoot frequency in oak saplings and minimum temperature observed in April. There was also a trend of increasing flag-shoot frequency from south to north which matches with an optimum in summer temperature that is moderate (an average of maximal daily temperature in June to August of $22.5^{\circ} \mathrm{C}$ ). However, the significant effect of latitude should be interpreted with caution because few plots were observed in the southern part of the country where natural regenerations of sessile or pedunculate oak are not frequent.
In addition to climate effects, we showed that E. quercicola and flag-shoot frequencies were significantly affected by site factors acting at a lower spatial scale. Altogether, flag-shoots could be found in approximately half of the stands. We did not explore in detail the stand or site factors that might explain the local frequency of flag-shoot. However, we found that this frequency was strongly affected by sapling height: flag-shoots and E. quercicola were found mostly in stands with saplings of 10 to $70 \mathrm{~cm}$ in height $(98 \%$ of flag-shoots were observed on saplings in that height range). This result is intriguing because such a relationship has not been reported for flag-shoots induced by other powdery mildew species. One possibility is that sapling height is spuriously related to flag-shoot density because of its relationship with tree density in the plot. The typical regeneration process of managed oak stands lasts approximately 5 to 8 years, during which seed trees are progressively felled once saplings have established from acorns, in order to limit shading. The tree density effect is therefore partially taken into account by the sapling height effect. The density of seed trees likely affects the microclimate and may provide protection against $\mathrm{UVb}$ through shading or, alternatively, represent a source of inoculum for saplings. However, a survey of seed trees for powdery mildew presence showed that they were mainly infected by E. alphitoides, with very limited infection by E. quercicola (M. L. Desprez-Loustau, unpublished results). Presence of $E$. quercicola has been documented on mature trees (Mougou-Hamdane et al. 2010) but may represent a scarce inoculum, which explains the patchy distribution of this species

TABLE 4. Results of the logistic regression on the proportion of Erysiphe lesions with Erysiphe quercicola presence in oak regenerations ${ }^{\mathrm{a}}$

\begin{tabular}{lcc}
\hline Variable $^{\mathrm{b}}$ & Mean $(\mathrm{SD})^{\mathrm{c}}$ & $95 \% \mathrm{CI}^{\mathrm{d}}$ \\
\hline$\mu$ & $2.79(16.07)$ & $-26.86 ; 36.83$ \\
$y e(2012)$ & $-0.30(0.19)$ & $-0.66 ;-0.05$ \\
$y e(2013)$ & $0.30(0.19)$ & $0.05 ; 0.66$ \\
$l g$ & $-0.53(0.21)$ & $-0.96 ;-0.15$ \\
$l t$ & $0.03(0.35)$ & $-0.78 ; 0.59$ \\
$q u(1)$ & $-2.50(1.00)$ & $-4.67 ;-0.79$ \\
$q u(2)$ & $0.75(0.76)$ & $-0.80 ; 2.24$ \\
$q u(3)$ & $1.75(0.79)$ & $0.44 ; 3.51$ \\
$b$ & $4.40(3.62)$ & $0.14 ; 13.29$ \\
$c$ & $0.47(0.29)$ & $0.05 ; 1.28$ \\
$\sigma$ & $4.97(3.26)$ & $1.57 ; 12.74$
\end{tabular}

a The model deviance information critera (DIC) is of 147.0.

b Abbreviations: $q u(1)=$ pure Quercus robur plots, $q u(2)=$ mixed $Q$. robur $Q$. petraea plots, and $q u(3)=$ pure $Q$. petraea plots. $\mathrm{R}_{\text {hat }}$ were all close to 1 , indicating that the Markov chain Monte Carlo chains converged (GelmanRubin test).

c $\mathrm{SD}=$ standard deviation

${ }^{\mathrm{d}} \mathrm{CI}=$ credibility interval.
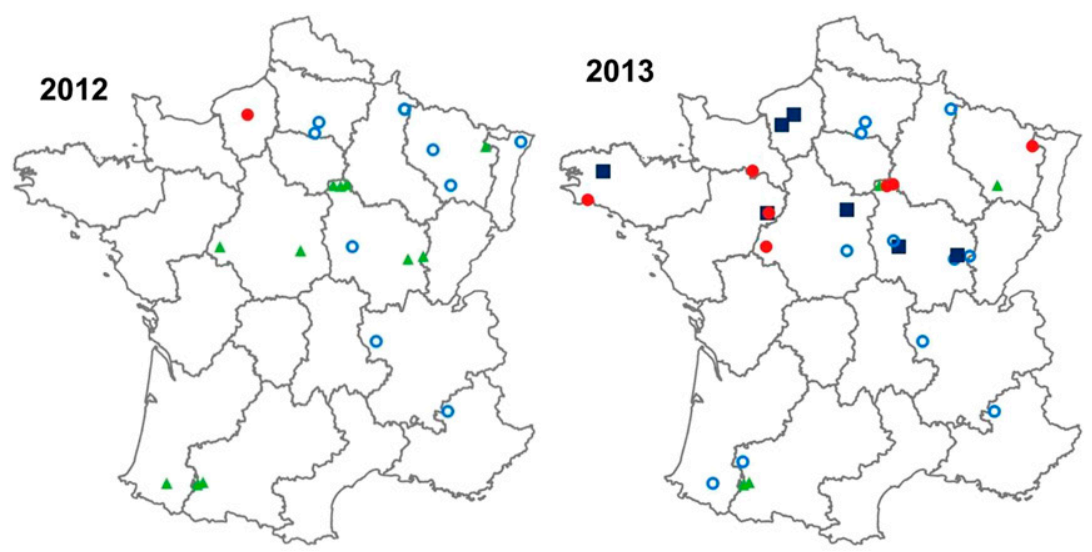

Fig. 4. Relative frequency of Erysiphe quercicola in the regeneration survey. Percentage of analyzed infected samples where E. quercicola was detected in spring of each year: None $(\bigcirc), 1$ to $50 \%(\boldsymbol{\Delta}), 50$ to $90 \%(\bullet)$, and $>90 \%(\bullet)$. 
in stands with natural regeneration. It has to be pointed out that a model including tree density instead of sapling height provided a poorer fit to the data and, thus, we did not find a strong support for the hypothesis that seed tree density is the driving factor behind the sapling height effect. It is also possible that microclimate close to the ground, with higher humidity, may provide good conditions for E. quercicola development. Finally, height may reflect an ontogenic (age) effect. Oak trees show a rhythmic growth with a variable number of flushes in the season, generally decreasing with age (Collet et al. 1997). Strong interactions between oak growth dynamics and powdery mildew infection have been shown (Desprez-Loustau et al. 2014). The occurrence of several flushes in young saplings can be hypothesized to favor bud infection by E. quercicola.

Another stand effect that we found to be important was the clear host preference of E. quercicola for $Q$. petraea. This is in contrast to the general observation that $Q$. robur is more susceptible to powdery mildew than Q. petraea (Marçais and Desprez-Loustau 2014). This suggests that the host specificity of E. alphitoides and E. quercicola are slightly different, the former being better adapted to $Q$. robur and the latter to $Q$. petraea. Different host preferences between E. alphitoides and E. quercicola were also reported within their putative area of origin in Japan (e.g., Q. phillyraeoides is only infected by E. quercicola) (Takamatsu et al. 2015).

TABLE 5. Relationship between climatic parameters and the proportion of Erysiphe lesions with Erysiphe quercicola presence in oak regenerations

\begin{tabular}{lrcc}
\hline Models $^{\mathrm{a}}$ & Mean $(\mathrm{SD})^{\mathrm{b}}$ & $95 \% \mathrm{CI}^{\mathrm{c}}$ & $\mathrm{DIC}^{\mathrm{d}}$ \\
\hline SR.sum & $-0.22(0.23)$ & $-0.67 ; 0.22$ & 147.7 \\
TM.sum & $0.39(0.43)$ & $-0.42 ; 1.25$ & 146.7 \\
TX.sum & $0.06(0.43)$ & $-0.75 ; 0.96$ & 146.4 \\
$\log (-$ MinT.spr) & $-0.72(0.44)$ & $-1.60 ; 0.10$ & 149.5 \\
SR.spr & $0.35(0.25)$ & $-0.11 ; 0.87$ & 147.3 \\
TM.spr & $-0.17(0.48)$ & $-1.15 ; 0.74$ & 147.4 \\
$\log (-$-sNDT.win) & $-1.19(0.33)$ & $-1.84 ;-0.55$ & 144.8 \\
$\log (-$ MinT.win) & $-0.87(0.25)$ & $-1.36 ;-0.38$ & 146.6 \\
TM.win & $1.39(0.44)$ & $0.57 ; 2.32$ & 148.2 \\
\hline
\end{tabular}

a TM.sum, TX.sum, and SR.sum $=$ average of mean or maximal daily temperature and sum of daily rain, respectively, in the previous year summer; MinT.spr $=$ minimal temperature reached in April; SR.spr and TM.spr $=$ sum of daily rain and average daily mean temperature, respectively, from 15 April to 15 May; TM. win = average of mean daily temperature; MinT.win = minimal temperature reached; and sNDT.win = sum of negative minimal daily temperatures in winter. $R_{\text {hat }}$ were all close to 1 , indicating that the Markov chain Monte Carlo chains converged (Gelman-Rubin test).

b $\mathrm{SD}=$ standard deviation.

${ }^{c} \mathrm{CI}=$ credibility interval

${ }^{\mathrm{d}}$ Deviance information critera (DIC).
The strong stand effect might also reflect a stochastic effect of E. quercicola introduction in oak stands with poor subsequent longdistance dispersal of the pathogen. Although the cycle of E. quercicola remains poorly documented, empirical and theoretical evidence point to a lesser dispersal capacity or competitive ability of this pathogen compared with E. alphitoides during the growing season (Hamelin et al. 2016). We observed that flag-shoots present a strong aggregated pattern, a fact that was already reported for other powdery mildews (Cortesi et al. 2004). Also, in accordance with previous results (Feau et al. 2012), the proportion of E. quercicola within Erysiphe spp. decreased during the vegetative season. These patterns might be explained by the fact that reinitiation of epidemics each spring by E. quercicola relies on only a few rare flag-shoots. In contrast, chasmothecia produced by E. alphitoides at the end of the season (Marçais et al. 2009) are potentially well distributed throughout stands and, thus, can initiate many disease foci in the following spring by airborne ascospores.

A low epidemiological potential of E. quercicola may explain why, contrary to our hypothesis, E. quercicola or flag-shoot frequency in spring could not explain the severity of powdery mildew epidemics at the end of the season, despite the wide range in the proportion of Erysiphe lesions with E. quercicola presence that we

TABLE 6. Effect of Erysiphe alphitoides prevalence in spring (Sp) and cooccurrence of E. alphitoides and E. quercicola in the plot (Co), in addition to year, geography, and host species effects on oak mildew severity at the end of the summer in stands of the regeneration survey (deviance information critera (DIC) of -96.6)

\begin{tabular}{lrc}
\hline Variable $^{\mathrm{a}}$ & Mean $(\mathrm{SD})^{\mathrm{b}}$ & $\mathrm{Q} 2.5-\mathrm{Q} 97.5$ \\
\hline$\mu$ & $-6.78(2.75)$ & $-11.95 ;-1.36$ \\
$y e(2012)$ & $0.22(0.10)$ & $0.02 ; 0.41$ \\
$y e(2013)$ & $-0.22(0.10)$ & $-0.41 ;-0.02$ \\
$l g$ & $-0.03(0.05)$ & $-0.12 ; 0.07$ \\
$l t$ & $0.09(0.05)$ & $-0.01 ; 0.18$ \\
$q u(1)$ & $0.06(0.17)$ & $-0.28 ; 0.40$ \\
$q u(2)$ & $-0.15(0.22)$ & $-0.59 ; 0.26$ \\
$q u(3)$ & $0.09(0.16)$ & $-0.22 ; 0.42$ \\
Plant & $-0.28(0.22)$ & $0.72 ; 0.15$ \\
Sp & $0.90(0.35)$ & $0.21 ; 1.60$ \\
Co & $0.29(0.32)$ & $-0.35 ; 0.90$ \\
$\sigma$ & $0.19(0.15)$ & $0.03 ; 0.55$ \\
\hline
\end{tabular}

a Abbreviations: $q u(1)=$ pure Quercus robur plots, $q u(2)=$ mixed $Q$. roburl $Q$. petraea plots, and $q u(3)=$ pure $Q$. petraea plots. Sp indicates the prevalence of E. alphitoides (PrevEA), and Co and Plant are indicator variables taking a value of 1 if co-occurrence of the two Erysiphe spp. occurred in the stand or if the stand was a plantation, respectively. $\mathrm{R}_{\text {hat }}$ were all close to 1 , indicating that the Markov chain Monte Carlo chains converged (Gelman-Rubin test).

b $\mathrm{SD}=$ standard deviation.
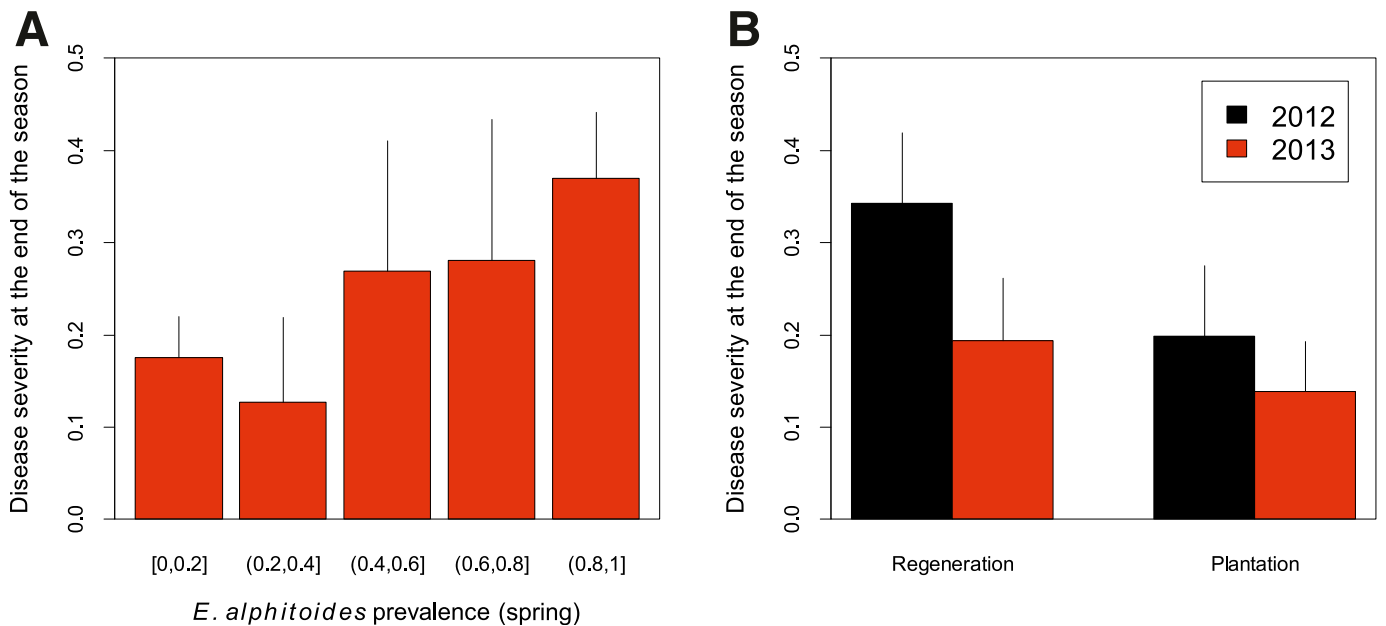

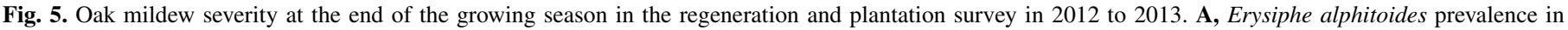
spring and $\mathbf{B}$, year and survey effects. 
observed in spring (from 0 to 1 ). Moreover, the co-occurrence of the two pathogens in a stand did not influence the final disease severity, unlike what was reported in several other pathosystems (Tollenaere et al. 2016). Thus, our results suggest a minor role of E. quercicola in the oak powdery mildew epidemics. However, it must be pointed out that E. quercicola was never observed to be present alone, in the absence of E. alphitoides, in any of the surveyed plots. Maybe this species would gain some importance in the absence of E. alphitoides. Interestingly, the prevalence of E. alphitoides in spring was significantly related to the disease severity at the end of the season, although the relationship was not very tight. This shows an analogy with grapevine powdery mildew, where disease severity was shown to be positively related to the spring frequency of the biotype reproducing sexually by chasmothecia and not the one only found in flag-shoots (Montarry et al. 2008, 2009). An alternative hypothesis to the one we tested to explain the positive relationship between mild winters and disease peaks could be that winter conditions may influence early infections by E. alphitoides which, in turn, are associated with higher disease severity at the end of the season. Cold winters have been shown to limit powdery mildew overwintering not only in buds but also through limited survival of mycelium in leaves (Asher and Williams 1991) or of chasmothecia (Mmbaga 2002; Penczykowski et al. 2015). Moreover, winter temperatures might act through phenological synchrony between bud break and ascospore release from E. alphitoides chasmothecia, which was shown to be critical for the initiation of epidemics (Desprez-Loustau et al. 2010; Marçais et al. 2009).

In conclusion, our results did show improved survival of E. quercicola after mild winters but disease severity could not be related to any complementarity effect between the two Erysiphe spp. in the pathogenic complex causing oak powdery mildew. However, our results are in line with several other recent studies pointing to the critical role of between-season transmission and primary inoculum to explain disease dynamics (Hamelin et al. 2011; Mailleret et al. 2012; Penczykowski et al. 2015; Tack and Laine 2014). This could be very significant in a climate change context, in particular with winter warming (Desprez-Loustau et al. 2007; Penczykowski et al. 2015). Although survival during the dormant season is known to be important for plant disease dynamics, it is often not taken into account in epidemiological models.

\section{ACKNOWLEDGMENTS}

We thank the DSF, Ministry of Agriculture for financial support and the DSF observers who supported this work by collecting samples and disease data. Additional financial support came from the CLIF contract from the INRA metaprogram ACCAF. The UMR IAM is supported by a grant overseen by the French National Research Agency (ANR) as part of the "Investissements d'Avenir" program (ANR-11-LABX-0002-01, Laboratory of Excellence ARBRE).

\section{LITERATURE CITED}

Agrios, G. N. 2005. Plant Pathol. 5: Elsevier Academic Press.

Asher, M. J. C., and Williams, G. E. 1991. Forecasting the national incidence of sugar-beet powdery mildew from weather data in Britain. Plant Pathol. 40:100-107.

Bearchell, S. J., Fraaije, B. A., Shaw, M. W., and Fitt, B. D. 2005. Wheat archive links long-term fungal pathogen population dynamics to air pollution. Proc. Natl. Acad. Sci. USA 102:5438-5442.

Collet, C., Colin, F., and Bernier, F. 1997. Height growth, shoot elongation and branch development of young Quercus petraea grown under different levels of resource availability. Ann. For. Sci. 54:65-81.

Cortesi, P., Ottaviani, M. P., and Milgroom, M. G. 2004. Spatial and genetic analysis of a flag shoot subpopulation of Erysiphe necator in Italy. Phytopathology 94:544-550.

Covey R. P. 1969. Effect of extreme cold on the overwintering of Podosphaera leucotricha. Plant Dis. Rep. 53:710.

Crous, P. W., Groenewald, J. Z., Mansilla, J. P., Hunter, G. C., and Wingfield, M. J. 2004. Phylogenetic reassessment of Mycosphaerella spp. and their anamorphs occurring on Eucalyptus. Stud. Mycol. 50:195-214.
Délye, C., and Corio-Costet, M.-F. 1998. Origin of primary infections of grape by Uncinula necator: RAPD analysis discriminates two biotypes. Mycol. Res. 102:283-288.

Desprez-Loustau, M.-L., Vitasse, Y., Delzon, S., Capdevielle, X., Marçais, B., and Kremer, A. 2010. Are plant pathogen populations adapted for encounter with their host? A case study of phenological synchrony between oak and an obligate fungal parasite along an altitudinal gradient. J. Evol. Biol. 23:87-97.

Desprez-Loustau, M.-L., Robin, C., Renaud, G., Déqué, M., Badeau, V., Piou, D., Husson, C., and Marçais, B. 2007. Simulating the effects of a climate change scenario on geographical range and activity of forest pathogenic fungi. Can. J. Plant Pathol. 29:101-120.

Desprez-Loustau, M.-L., Saint-Jean, G., Barres, B., Dantec, C., and Dutech, C. 2014. Oak powdery mildew changes growth patterns in its host tree: Host tolerance response and potential manipulation of host physiology by the parasite. Ann. For. Sci. 71:563-573.

Fabre, B., Ioos, R., Piou, D., and Marçais, B. 2012. Is emergence of pine Dothistroma needle blight in France caused by the cryptic species Dothistroma pini? Phytopathology 102:47-54.

Feau, N., Decourcelle, T., Husson, C., Desprez-Loustau, M.-L., and Dutech, C. 2011. PHYLORPH: Finding single copy genes out of sequenced genomes for multilocus phylogenetics in non model fungi. PLoS One 6:e18803.

Feau, N., Lauron-Moreau, A., Piou, D., Marçais, B., Dutech, C., and Desprez-Loustau, M.-L. 2012. Niche partitioning of genetic lineages involved in the oak powdery mildew complex. Fungal Ecol. 5:154-162.

Fitt, B. D., Huang, Y., van den Bosch, F., and West, J. S. 2006. Coexistence of related pathogen species on arable crops in space and time. Annu. Rev. Phytopathol. 44:163-82.

Hamelin, F. M., Bisson, A., Desprez-Loustau, M.-L., Fabre, F., and Mailleret, L. 2016. Temporal niche differentiation of parasites sharing the same plant host: Oak powdery mildew as a case study. Ecosphere 7:e0151.

Hamelin, F. M., Castel, M., Poggi, S., Andrivon, D., and Mailleret, L. 2011. Seasonality and the evolutionary divergence of plant parasites. Ecology 92: 2159-2166.

Hersh, M. H., Vilgalys, R., and Clark, J. S. 2012. Evaluating the impacts of multiple generalist fungal pathogens on temperate tree seedling survival. Ecology 93:511-520.

Heuser, T., and Zimmer, W. 2002. Quantitative analysis of phytopathogenic ascomycota on leaves of pedunculate oaks Quercus robur L. by real-time PCR. FEMS Microbiol. Lett. 209:295-299.

Jarvis, W. R., Gubler, W. G., and Grove, G. G. 2002. Epidemiology of powdery mildews in agricultural pathosystems. Pages 169-199 in: The Powdery Mildews: A Comprehensive Treatise. R. R. Bélanger, W. R. Bushnell, A. J. Dik, and T. L. W. Carver, eds.

Johnson, P. T. J., and Hoverman, J. T. 2012. Parasite diversity and coinfection determine pathogen infection success and host fitness. Proc. Natl. Acad. Sci. USA 109:9006-9011.

Khairi, S. M., and Preece, T. F. 1978. Hawthorn powdery mildew: Overwintering mycelium in buds and the effect of clipping hedges on disease epidemiology. Trans. Br. Mycol. Soc. 71:399-404.

Liyanage, A. de S., and Royle, D. J. 1976. Overwintering of Sphaerotheca humuli, the cause of hop powdery mildew. Ann. Appl. Biol. 83:381-394.

Lonsdale, D. 2015. Review of oak mildew, with particular reference to mature and veteran trees in Britain. Arboricult. J. 37:61-84.

López-Villavicencio, M., Jonot, O., Coantic, A., Hood, M. E., Enjalbert, J., and Giraud, T. 2007. Multiple infections by the anther smut pathogen are frequent and involve related strains. PLoS Pathog. 3:e176.

Loreau, M., and Hector, A. 2001. Partitioning selection and complementarity in biodiversity experiments. Nature 412:72-76.

Mailleret, L., Castel, M., Montarry, J., and Hamelin, F. M. 2012. From elaborate to compact seasonal plant epidemic models and back: Is competitive exclusion in the details? Theor. Ecol. 5:311-324.

Marçais, B., Caël, O., and Delatour, C. 2011. Interaction between root rot basidiomycetes and Phytophthora species on pedunculate oak. Plant Pathol. 60:296-303.

Marçais, B., and Desprez-Loustau, M.-L. 2014. European oak powdery mildew: Impact on trees, effects of environmental factors, and potential effects of climate change. Ann. For. Sci. 71:633-642.

Marçais, B., Husson, C., Godart, L., and Caël, O. 2016. Influence of site and stand factors on Hymenoscyphus fraxineus induced basal lesions. Plant Pathol. 65:1452-1461.

Marçais, B., Kavkova, M., and Desprez-Loustau, M.-L. 2009. Phenotypic variation in the phenology of ascospore production between European populations of oak powdery mildew. Ann. For. Sci. 66:814-822.

Mmbaga, M. T. 2002. Ascocarp formation and survival and primary inoculum production in Erysiphe (sect. Microsphaera) pulchra in dogwood powdery mildew. Ann. Appl. Biol. 141:153-161.

Montarry, J., Cartolaro, P., Delmotte, F., Jolivet, J., and Willocquet, L. 2008. Genetic structure and aggressiveness of Erysiphe necator populations during grapevine powdery mildew epidemics. Appl. Environ. Microbiol. 74:6327-6332. 
Montarry, J., Cartolaro, P., Richard-Cervera, S., and Delmotte, F. 2009. Spatiotemporal distribution of Erysiphe necator genetic groups and their relationship with disease levels in vineyards. Eur. J. Plant Pathol. 123:61-70.

Mougou, A., Dutech, C., and Desprez-Loustau, M.-L. 2008. New insights into the identity and origin of the causal agent of oak powdery mildew in Europe. For. Pathol. 38:275-287.

Mougou-Hamdane, A., Giresse, X., Dutech, C., and Desprez-Loustau, M.-L. 2010. Spatial distribution of genetically differentiated groups of oak powdery mildew fungi in France, using quick molecular detection methods. Ann. For. Sci. 67:212.

Pedersen, A. B., and Fenton, A. 2007. Emphasizing the ecology in parasite community ecology. Trends Ecol. Evol. 22:133-139.

Penczykowski, R. M., Walker, E., Soubeyrand, S., and Laine, A. L. 2015. Linking winter conditions to regional disease dynamics in a wild plantpathogen metapopulation. New Phytol. 205:1142-1152.

Pérez, G., Slippers, B., Wingfield, M. J., Wingfield, B. D., Carnegie, A. J., and Burgess, T. I. 2012. Cryptic species, native populations and biological invasions by a eucalypt forest pathogen. Mol. Ecol. 21:4452-4471.

Sall, M. A., and Wrysinski, J. 1982. Perennation of powdery mildew in buds of grapevines. Plant Dis. 66:678-679.

Savary, S., Teng, P. S., Willocquet, L., and Nutter, F. W., Jr. 2006. Quantification and modeling of crop losses: A review of purposes. Annu. Rev. Phytopathol. 44:89-112.

Seabloom, E. W., Borer, E. T., Mitchell, C. E., and Power, A. G. 2010. Viral diversity and prevalence gradients in North American Pacific Coast grasslands. Ecology 91:721-732.

Spotts, R. A., and Chen, P. M. 1984. Cold hardiness and temperature responses of healthy and mildew-infected terminal buds of apple during dormancy. Phytopathology 74:542-544.

Susi, H., Barrès, B., Vale, P. F., and Laine, A. L. 2015. Co-infection alters population dynamics of infectious disease. Nat. Commun. 6: Article number 5975. doi: $10.1038 /$ ncomms6975
Syller, J. 2012. Facilitative and antagonistic interactions between plant viruses in mixed infections. Mol. Plant Pathol. 13:204-216.

Tack, A. J., and Laine, A. L. 2014. Ecological and evolutionary implications of spatial heterogeneity during the off-season for a wild plant pathogen. New Phytol. 202:297-308.

Takamatsu, S., Braun, U., Limkaisang, S., Kom-Un, S., Sato, Y., and Cunnington, J. H. 2007. Phylogeny and taxonomy of the oak powdery mildew Erysiphe alphitoides sensu lato. Mycol. Res. 111: 809-826.

Takamatsu, S., Ito, H., Shiroya, Y., Kiss, L., and Heluta, V. 2015. First comprehensive phylogenetic analysis of the genus Erysiphe (Erysiphales, Erysiphaceae) I. The Microsphaera lineage. Mycologia 107: 475-489.

Tollenaere, C., Susi, H., and Laine, A.-L. 2016. Evolutionary and epidemiological implications of multiple infection in plants. Trends Plant Sci. 21: 80-90.

Tollenaere, C., Susi, H., Nokso-Koivisto, J., Koskinen, P., Tack, A., Auvinen, P., Paulin, L., Lehtonen, R., and Laine, A.-L. 2012. SNP Design from 454 sequencing of Podosphaera plantaginis transcriptome reveals a genetically diverse pathogen metapopulation with high levels of mixed-genotype infection. PLoS One 7:e52492.

Vettraino, A. M., Barzanti, G. P., Bianco, M. C., Ragazzi, A., Capretti, P., Paoletti, E., Luisi, N., Anselmi, N., and Vannini, A. 2002. Occurrence of Phytophthora species in oak stands in Italy and their association with declining oak trees. For. Pathol. 32:19-28.

Wong, M.-H., Crous, P. W., Henderson, J., Groenewald, J. Z., and Drenth, A. 2012. Phyllosticta species associated with freckle disease of banana. Fungal Divers. 56:173-187.

Xu, C., Wang, C., Ju, L., Zhang, R., Biggs, A. R., Tanaka, E., Li, B., and Sun, G. 2015. Multiple locus genealogies and phenotypic characters reappraise the causal agents of apple ring rot in China. Fungal Divers. 71: $215-231$. 